\section{Sebastián Parga}

sparga@cpabogados.cl

\section{Francisco Plass}

fplass@cpabogados.cl

Recibido: 07.06.19

Aceptado: 23.07.19

\title{
El uso y control de correos electrónicos en el ámbito laboral
}

\section{Use and control of institutional email in the work environment.}

Resumen: El avance tecnológico en las últimas décadas ha originado, en el marco de la relación laboral, tanto para la doctrina como para la jurisprudencia, la necesidad de resolver el creciente conflicto entre la propiedad del empleador y la privacidad del trabajador. Este trabajo pretende desarrollar este conflicto, particularmente centrado en el correo electrónico como herramienta de trabajo, intentando dilucidar los conceptos de privacidad y potestad de mando y dirección que posee el empleador sobre la revisión y control de correos electrónicos. La propuesta se basa en la idea de que la inviolabilidad de toda forma de comunicación privada pretende proteger un espacio íntimo, pero no de forma absoluta, toda vez que el empleador puede ejercer medidas de control sobre los correos electrónicos institucionales. Como consecuencia de esta disputa o conflicto de intereses, se propone un análisis particular respecto de cada caso en que existan indicios de vulneración a la privacidad, determinando si la medida adoptada por el empleador tiene justificación, es necesaria y proporcionada.

Palabras clave: relación laboral; correo electrónico; privacidad; medidas de control.
Abstract: Regarding the relationship between labor relations and the technological advance in the last decades, a new concern has emerged. It has become necessary to solve increasing conflicts between the employer's property and the worker's privacy, and to understand this conflict under the lens of Doctrine and Jurisprudence. This article intends to be explanatory of this conflict, focusing particularly on the e-mail as a tool require at work. Clarifying the concepts of privacy, supervising faculty and direction the employer has over emails that circulate through the institutional email. The proposal is based on the idea that the inviolability of any private communication aims to protect private space. However, not completely, since the employer can manage control measures over institutional emails. As a result of this dispute or conflict of interests, an analysis is presented, which shows different cases that evince infringement of privacy, and determines whether the measure adopted by the employer is justified, necessary and proportionate. Keywords: employment relationship; emails; privacy; control measures. 
El derecho del trabajo siempre ha pretendido, mediante un fortalecimiento de lo colectivo y a través del establecimiento de mínimoslegales indisponibles, devolver al trabajador la libertad que ha perdido al someterse a las órdenes y directrices de un tercero, su empleador ${ }^{1}$, el cual tiene incluso, en virtud de la ley y el propio contrato de trabajo, prerrogativas disciplinarias o sancionatorias con el objeto o finalidad de organizar la marcha de la empresa. Así las cosas, empleador y trabajador tienen derechos consagrados constitucionalmente y se deben respeto mutuo sobre ellos, sin embargo, en la práctica, tal dicotomía no ha sido pacífica.

En efecto, la empresa antes era concebida como un espacio en el cual el trabajador quedaba totalmente sometido a las órdenes del empleador, concibiéndose las garantías fundamentales de las que goza todo ciudadano como cuestiones para ejercer y exigir al salir de la empresa. Al respecto Baylos señala con elocuencia que:

el trabajador, al atravesar la puerta de la fábrica, queda sometido a una ley propia y específica en la que se establecen preceptos obligatorios sobre su comportamiento en casa de su señor, de tal forma que la fábrica aparecía como una zona franca y segregada de la sociedad civil (Baylos, 1991, p. 95).

Se ha indicado que esta forma de entender los derechos fundamentales se debía a dos razones. La primera de ellas consistía en que el derecho del trabajo era asociado comúnmente al derecho privado y, por tanto, los principios que inspiraban las relaciones laborales eran los propios del derecho civil, esto es la libertad contractual e igualdad jurídica de los contratantes. El trabajador se había obligado a trabajar en determinadas condiciones que debía cumplir, de lo contrario incumplía el contrato de trabajo y la ley. Las garantías fundamentales, en cambio, estaban relacionadas con el derecho público y el ejercicio de las libertades civiles. La segunda razón refería a que el modelo ideológico en que fueron concebidos los derechos fundamentales en un Estado liberal, era el de un mecanismo de protección del comerciante frente a la invasión estatal, por lo que en nada se relacionaba al prototipo social del derecho del trabajo (Ugarte, 2011, p. 119).

Por otra parte, se ha discutido mucho acerca del perjuicio que provoca la protección de los derechos de los trabajadores en desmedro del sector empresarial, produciendo una verdadera resistencia por parte de este último a cualquier limitación que pueda generarse a sus propios derechos. A tal punto es lo anterior, que el autor del Plan Laboral calificó las normas laborales y su finalidad de la siguiente forma:

La normativa laboral chilena fue hija de "corazones sangrantes" y de razonamientos débiles. Los textos de estudios parten invariablemente con inflamadas declaraciones de redención social. Pero nada dicen acerca de cómo mejorar en la realidad las condiciones de vida de la gente. No obstante que el mercado laboral es una realidad eminentemente económica puesto que juegan un rol clave los conceptos de costo, productividad, competencia y demanda- el lenguaje que se usa es de fibra inconfundiblemente emocional. No hay político, no hay abogado con "sensibilidad social", no hay agitador, no hay vicario "progresista" ni hay comunicador social de "avanzada", que no pueda dar en cualquier momento una encendida conferencia sobre el tema de la equidad en las relaciones laborales. Pero nunca estas proclamas contienen soluciones viables y coherentes a los problemas; son sólo expresión de buenos deseos (Piñera, 1990, p.25).

La realidad descrita no queda indiferente frente a las interrogantes que pretendemos resolver en este trabajo, pues la visión que se tenga respecto de un mayor o menor control de la actividad empresarial desde el punto de vista de la protección de los derechos del trabajador, se ve afectada al implementarse nuevas tecnologías y

\footnotetext{
${ }^{1}$ Al respecto Ugarte (2014, p. 5) señala: “...la explicación de aquello - de la prioridad de lo colectivo por sobre la intervención legal y su rol de motor de la evolución de este tipo de derecho - dice relación con el compromiso con la libertad que el Derecho del Trabajo supone: sólo en organización colectiva los trabajadores son capaces de sostener una acción que les restablezca aquello que la relación laboral les despoja: no estar sometido al poder arbitrario de otro".
} 
masificarse mecanismos tecnológicos, que llegan a ser herramientas fundamentales para el cumplimiento de la actividad diaria en una empresa. Sin duda que en la medida que se permita un mayor control o supervigilancia del empresario sobre las herramientas tecnológicas que usan sus dependientes (en principio legítima y necesaria y que emana del poder de mando y dirección, atributo del derecho de propiedad y libertad económica), deberá ponerse más atención, asimismo, a que dicho control o supervisión se haga respetando los derechos de los trabajadores en cuanto ciudadanos ${ }^{2}$; y en lo tocante a esta temática que nos ocupa, observando el derecho a la intimidad o privacidad.

Nuestra Constitución política consagra los derechos a la intimidad y privacidad en sus numerales $19 \mathrm{~N}^{\circ} 4 \mathrm{y}$ 5, y los describe como el respeto y protección a la vida privada y pública, honra de la persona y su familia, y la inviolabilidad del hogar y de toda forma de comunicación privada. Sin ánimo de ahondar mayormente en lo que este fenómeno implica, por exceder los fines de este trabajo, este tipo de derechos fueron

llamados por la doctrina comparada como derechos laborales inespecíficos, esto es, "aquellos otros derechos constitucionales de carácter general y, por ello, no específicamente laborales que pueden ser ejercidos, sin embargo, por los sujetos de las relaciones de trabajo (los trabajadores en particular) en el ámbito de las mismas", tales como la intimidad o la libertad de expresión" (Ugarte, 2011, p. 116). En el mismo sentido Gamonal señala: "la doctrina laboral, la jurisprudencia y también el legislador han aceptado con entusiasmo la aplicación horizontal de los derechos fundamentales no propiamente laborales como límite a los poderes del empleador. De esta forma junto con los derechos humanos laborales propiamente tales (por ejemplo, libertad de trabajo y su protección, la justa retribución y la libertad sindical), encontramos los derechos humanos que detenta el trabajador en cuanto persona y ciudadano, derechos civiles que no deberían quedar postergados por el hecho de ser parte de un contrato de trabajo, sin perjuicio de que sean adaptados, restringidos o modulados para dar cumplimiento al contrato (Gamonal, 2011, pp. 56-57).

Pues bien, a raíz de lo expuesto, los avances tecnológicos que se implementen en la empresa y la forma en que se utilicen en el trabajo, tendrán un impacto en los derechos de intimidad y privacidad de los trabajadores. Es así como se generará un conflicto constante entre los avances que pretenda establecer la empresa en este campo (referidos a mayor cantidad, mejores y más eficaces medios tecnológicos, junto con la posibilidad de exigir que se utilicen para la finalidad por la que fueron incorporados en la empresa) y los derechos de los trabajadores, quienes tienen derecho a exigir un trato digno y acorde a sus derechos fundamentales.

A propósito de lo expuesto, se ha señalado que el ingreso de las nuevas tecnologías a la relación laboral supone en sí una paradoja, ya que, por una parte, aumenta la autonomía de los trabajadores, quienes acceden a herramientas más eficientes permitiéndoles desempeñarse de mejor manera, pero por la otra, serán objeto de control por el empleador a través de ellas; y que por tanto exponen a nuevos riesgos los derechos de los trabajadores, particularmente a su intimidad y vida privada (Ugarte, 2011, p. 176). Estos derechos son la piedra angular del presente trabajo, ya que la regulación del uso de los correos electrónicos - por el empleadorincide en estas garantías fundamentales de sus dependientes. En este contexto, debemos dejar en claro que ya sea al momento de determinar las obligaciones y prohibiciones cuya transgresión puede importar un incumplimiento laboral (lo que normalmente se hará en el reglamento interno de orden, higiene y seguridad de la empresa), como al momento de calificarse un determinado incumplimiento por el empleador (lo que tendrá lugar en las amonestaciones, en el acto del despido y/o en la carta de despido), deben respetarse los derechos fundamentales de los trabajadores, lo cual respecto de los correos electrónicos y el derecho a privacidad o intimidad es sumamente delicado.

\footnotetext{
${ }^{2}$ Expresión utilizada por Ugarte para describir el fenómeno de "ciudadanía en la empresa" (2010, p. 1).
} 
En síntesis, en este trabajo se pretende dar cuenta del conflicto que se produce con las nuevas tecnologías al ingresar al trabajo - particularmente el correo electrónico como herramienta de trabajo - y la intimidad y privacidad, en su calidad de derechos fundamentales, de los cuales el trabajador desde luego es titular. Para efectos de lo anterior, comenzaremos dando un concepto de qué es lo que entendemos por privacidad, para posteriormente analizar la facultad de revisión de correos electrónicos por el empleador y sus fines. Finalmente, arribaremos a una conclusión que, sin adelantar demasiado, consistirá en que la respuesta supondrá siempre un examen de proporcionalidad entre las medidas desplegadas por el empleador para llevar adelante la empresa y custodiar su propiedad, y las exigencias reglamentarias y sanciones impuestas a los trabajadores que limitan o afectan sus derechos de intimidad o privacidad.

\section{El derecho fundamental a la intimidad y vida privada del trabajador}

Se suele señalar que todo ciudadano tiene derecho a la intimidad, a su vida privada o bien, a tener privacidad. Si bien la propia Constitución política de la república distingue estos conceptos como derechos distintos, en sus artículos $19 \mathrm{~N}^{\circ} 4$ (vida privada) y $19 \mathrm{~N}^{\circ} 5$ (intimidad), lo que se ve reforzado por las actas oficiales de la Comisión de Estudio de la Nueva Constitución ${ }^{3}$, a nuestro juicio dichas diferencias no resultan del todo claras y son irrelevantes para nuestro estudio.

En efecto, Martínez de Pisón (1997) explica que, si bien existe un nexo entre ambos, se trataría de derechos diversos ya que históricamente responderían a necesidades y exigencias no coincidentes. En efecto, junto con indicar que ambos derechos surgirían en épocas diversas, señala respecto de la privacidad que esta se asocia al espacio familiar, religioso y económico de las personas; todos espacios infranqueables para terceros ${ }^{4}$, mientras que, por otro lado, la intimidad sería un espacio interior asimilable a la conciencia, lo cual asocia los afectos y opiniones personales ${ }^{5}$. En razón de lo expuesto, para este autor se trataría claramente de nociones distintas, siendo la intimidad una noción más profunda de lo que implica o protege la privacidad, y los cuales resultan ser - en su opinión - para efectos de su satisfacción, complementarios e inseparables.

En España, Agustina (2009) ha señalado que se trata, efectivamente, de garantías fundamentales diversas y coincide en que la noción de intimidad es más profunda que la de privacidad. En efecto, el referido autor indica que la intimidad tendría un alcance netamente individual, mientras que por su lado, la privacidad se referiría a aquellos espacios en que existen relaciones

\footnotetext{
${ }^{3}$ Véase: Comisión de Estudio de un Anteproyecto de la Nueva Constitución. (1973) Acta Oficial № 129 páginas 6-10.

${ }^{4}$ Señala al efecto: "el deseo de vida privada surge con la lectura en familia de la Biblia, el diálogo interno con Dios, la reclusión interior y la escritura de diarios personales, en fin, con la ética protestante -mercantil, por encima de todo, sujeta al ahorro, al cálculo, a la honestidad y a los libros mercantiles- y con las exigencias sociales y políticas de la utopía burguesa en los siglos xvii y xviii, y materializada en el más puro sistema liberal del xix. El burgués precisa una esfera aislada, libre para el desarrollo de su conciencia religiosa y una vida privada intensa con su familia y con los más próximos" (Martínez de Pisón, 1997, p. 720).

5 "[L]a intimidad aparece en fechas recientes, en la sociedad posindustrial, como un nuevo giro, un nuevo repliegue del individuo sobre sí mismo abandonando la privacidad intersubjetiva para recluirse en su interior, en un nuevo espacio intrasubjetivo. Ya no es reclusión en la vida privada, en la vida amurallada con la familia y los amigos, sino en la vida interior, en lo más profundo de nuestro ser, en la intraconciencia, donde se examinan los afectos, los pensamientos, las opiniones personales. Y los recuerdos, las fantasías, donde soñamos, amamos y odiamos, y envidiamos. La persona encerrada en torno a sí misma. Dos ámbitos, dos espacios conceptuales bien delimitados, separados, pero también interrelacionados. Pues no hay intimidad sin vida privada, sin el lugar doméstico donde recluirse aún más. Como tampoco hay privacidad, ni se puede gozar de una vida privada sin algo de intimidad..." (Martínez de Pisón, 1997, p. 721).
} 
interpersonales pero que no se desea que sean conocidas por el público general ${ }^{6}$. Según puede advertirse, para este autor la intimidad sería una garantía más individual que la privacidad, sin embargo, no da criterios que permitan, frente a un caso práctico, dilucidar con certeza frente a cuál garantía se está en presencia.

En lo que respecta a nuestro país, si bien se ha reconocido esta diferencia, se ha hecho con distinciones terminológicas. En efecto, los autores Maqueo, Moreno y Recio (2017), denominan "derecho a la privacidad" lo que sería para el anterior autor la "intimidad", lo diferencian del "derecho a la vida privada", señalando que este último derecho tendría un alcance mayor al primero ${ }^{7}$, sin embargo, no dan mayores explicaciones en cuanto al contenido de cada derecho.

Según puede apreciarse, si bien los autores reseñados coinciden en que existiría una diferencia entre vida privada, privacidad e intimidad, existen diferencias terminológicas que dificultan arribar a una solución certera. Por otro lado, la técnica utilizada para explicar las nociones de cada derecho, esto es, mediante ejemplos concretos, impide obtener un concepto abstracto y general para todos los casos. Lo expuesto, sin duda, no es trivial por cuanto el no conocer con precisión en qué consiste cada derecho, asumiendo como cierto que son efectivamente garantías diversas, dificulta que tales derechos puedan ser efectivamente resguardados por el ordenamiento jurídico, lo que hace controvertible su contenido, alcance e incluso su existencia. Únicamente puede concluirse que la intimidad -o privacidad - sería algo más íntimo que la vida privada, sin embargo, ninguno de los autores comentados es capaz de explicarlo claramente.

Lo expuesto permite arribar a la conclusión que ha sido defendida por autores como Figueroa (2014) -y esta es que la distinción es irrelevante $-{ }^{8}$, ya que todas las nociones apuntarían -en nuestra opinión - al mismo bien jurídico protegido, que es un ámbito interno que se desea sustraer del conocimiento de terceros, y que necesita de la protección del derecho. En el mismo sentido Ugarte ha sostenido que debiesen ser usados todos aquellos conceptos -intimidad, privacidad y vida privada- como sinónimos en razón de proteger, como indicamos, el mismo bien jurídico?

En razón de lo señalado, y concordando con los últimos autores expuestos, para efectos del presente trabajo se entenderán como sinónimos los derechos a la privacidad, a la vida privada y a la intimidad, por referirse al mismo bien jurídico. Creemos, por tanto, que la inviolabilidad de toda comunicación privada pretende proteger un espacio privado al que tiene derecho toda persona y, por tanto, todo trabajador al interior de la empresa.

\footnotetext{
${ }^{6}$ En sus términos: "Respecto de la distinción entre intimidad y privacidad, aunque en el lenguaje ordinario sean utilizadas de forma indistinta, puede decirse que la noción de intimidad se refiere a una esfera mucho más individual, en tanto que la privacidad abarcaría una franja intermedia entre el ámbito estrictamente personal o individual y el espacio donde tiene lugar la actividad pública de la persona, es decir, donde existen relaciones interpersonales pero sin que se planteen como abiertas al conocimiento general” (Agustina, 2009, p. 8).

${ }^{7}$ Al efecto los autores señalaron: "...existe pleno consenso entre los tribunales internacionales de derechos humanos en el sentido de que se trata de un concepto amplio, no susceptible de definiciones exhaustivas, y cuyo contenido es más extenso que el del derecho a la privacidad. De tal forma que se reconoce que el derecho a la vida privada y la privacidad no son sinónimos, a pesar de que el primero tiene un alcance mucho mayor que, en consecuencia, comprende al segundo..." (Maqueo, Moreno y Recio, 2017).

${ }^{8}$ En efecto, Figueroa señala a este respecto: “...la mayoría de la doctrina no distingue privacidad de intimidad y parece haber buenas razones para ello: no hay criterios analíticos para apoyar la distinción...varios autores sugieren que la intimidad corresponde a un ámbito o espacio inaccesible: la conciencia. Se trata de una idea improductiva porque, si la intimidad fuera un espacio inaccesible, entonces sería invulnerable y si fuera invulnerable, no requeriría de protección por parte del derecho positivo y ni siquiera sería de su incumbencia...En resumen, o la intimidad es tan revelable o accesible como la privacidad - y en tal caso no tiene sentido distinguirlas - o es fácticamente inaccesible, no teniendo entonces relevancia para el Derecho...dado que la Constitución emplea la expresión vida privada, que es equivalente a privacidad, no se justifica recurrir a otra nomenclatura" (Figueroa, 2014, pp. 47-48).

${ }^{9}$ En dicho sentido Ugarte señaló: "En nuestro país, y para zanjar de partida este problema atendido el objetivo central de estas líneas, daremos a ambas expresiones un mismo sentido, entendiendo que se refieren al mismo objeto jurídico de protección” (Ugarte, 2000, www.dt.gob.cl/1601/articles-65179_recurso_1.pdf).
} 


\section{Contenido y alcance de la privacidad}

Una vez aclarado conceptualmente cuál es la garantía fundamental que será objeto de este trabajo, a continuación corresponde dilucidar su contenido y sus límites, particularmente, si los correos electrónicos que utiliza un trabajador en una relación laboral forman parte de su ámbito de protección. Para el profesor Cea Egaña, el concepto de privacidad contemplado en la Constitución es un derecho amplio que se encuentra abierto a innovaciones tecnológicas como serían los correos electrónicos. En efecto, sostiene:

En términos generales, puede afirmarse que está consagrada en Chile desde la Constitución de 1828 y no ha dado lugar a problemas graves ni a interpretaciones rebuscadas. Sin embargo, tuvo razón la Comisión de Estudio al infundirle un significado amplio y abierto, pues sólo así quedarán comprendidos en ella, v.gr., los dispositivos electrónicos ultra sensibles con los cuales se puede violar el hogar y las comunicaciones privadas (Cea, 2003, p. 194).

Actualmente, la doctrina es unánime en considerar que la correspondencia y, por lo tanto, los correos electrónicos están incluidos dentro del contenido protegido por la privacidad como derecho fundamental. Al respecto Figueroa señala que un objeto será protegido dentro del ámbito de la privacidad cuando este sea un "objeto personal", el cual define como: "aquellos sobre los cuales la persona tiene algún derecho de uso exclusivo, aunque no necesariamente la propiedad, y sobre los cuales tiene un interés de privacidad" (Figueroa, 2014, p. 115) y para ello da expresamente como ejemplo la correspondencia (p.115). En el mismo sentido, Ugarte indica que dentro del ámbito protegido por el derecho a la privacidad en una relación laboral se encuentran los correos electrónicos indicando: "Para decirlo de un modo sencillo, que el empleador no intrusee [sic] el correo electrónico del trabajador es una exigencia de la privacidad -o del secreto de las comunicaciones, según corresponda- como espacio secreto..." (Ugarte, 2011, p.17).
En un sentido diverso al indicado previamente, Desdentado y Muñoz indican que: "no existe un derecho fundamental a utilizar los medios de comunicación para usos personales, sin perjuicio de que ese derecho pueda atribuirse a través de regulaciones infra constitucionales" (Desdentado y Muñoz, 2012, p. 192). Lo expuesto por estos autores es llamativo, ya que no sería parte de la garantía constitucional de privacidad el uso del correo electrónico entregado por el empleador para fines personales, siendo irrelevante - al parecer - el contenido de la información contenida en él. Sin embargo, si de todos modos el trabajador utiliza el correo corporativo para fines personales, ya sea por desconocimiento de las normas internas que dictaminan lo contrario, o bien porque existiendo estas se tolera dicha práctica, los autores aludidos señalan: "[l]a solución ha de buscarse, como en el caso de la intimidad, a partir de las expectativas de secreto que existan en la empresa en la utilización del correo por los trabajadores" (Desdentado y Muñoz, 2012, p. 195). En el mismo sentido Agustina indica: "[e]n cualquier caso, el empresario puede blindarse frente a las posibles acciones por vulneración de la privacidad mediante la comunicación oportuna del programa de monitorización que se vaya a llevar a cabo" (Agustina, 2009, p. 114).

Como puede apreciarse, a juicio de los autores españoles recién citados, la vulneración a la privacidad del trabajador a través de la revisión de sus correos electrónicos sería una cuestión para determinar con base en la expectativa de privacidad que poseería el trabajador y que, incluso, el empleador puede "blindarse" si comunica oportunamente que puede realizar revisiones. En consecuencia, los correos electrónicos solo serán parte del ámbito protegido por la garantía de privacidad si es que existía una legítima expectativa de privacidad en cuanto a su utilización. Lo anterior tiene lógica, pero nos parece que el simple hecho de "informar" o "advertir" al trabajador que se revisarán los medios de comunicación que utiliza en la empresa no hace que dicha actuación sea legítima y proporcional. 
En este mismo sentido, el Tribunal Constitucional español, en sentencia de 12 enero 2016, número 170/2013, señaló que la expectativa de privacidad de un trabajador desaparecía cuando se sancionaba la conducta del uso privado del correo electrónico de la empresa. Este caso versó sobre un trabajador que reveló a la competencia información confidencial a través del correo electrónico de la empresa. Cabe puntualizar que en el convenio colectivo aplicable a la empresa se sancionaba la conducta del uso privado del correo electrónico de la compañía, por lo que el Tribunal Constitucional comprendió que la expectativa de privacidad del trabajador desaparecía, con lo que no se vulneraba su derecho a la intimidad ${ }^{10}$.

Analizando lo que ocurre en nuestro país, una sentencia del Juzgado de Letras del Trabajo de Valparaíso, de fecha 8 de junio de 2009, en causa RIT: T-8-2009, caratulada: "Morales Aravena, Roxana María con Kirschfink, Irmgard Anne" establece que el empleador puede, por el carácter de "herramienta de trabajo" del correo electrónico, establecer cualquier tipo de revisión a los correos electrónicos de los trabajadores, en tanto Outlook es precisamente un medio de trabajo entregado por el empleador al trabajador.

Por otra parte, una sentencia del Juzgado de Letras del Trabajo de Copiapó, de fecha 15 de septiembre de 2008, causa rit T-1-2008, caratulada "Obregón con Kronos Limitada", condena a la empresa de vulneración a la privacidad. Este caso se trató de una trabajadora que en un chat messenger de uso general en la empresa, envió un mensaje a una amiga que trabajaba en una empresa fiscalizada por su empleadora, alertando de los problemas que existirían entre dos ejecutivos de dichas empresas, situación que denunciaba un dependiente de Kronos a la referida empresa fiscalizada. El jefe de proyecto de Kronos descubrió los chats y la trabajadora fue despedida. Esta sentencia establece que el control de tales comunicaciones no estaba regulada en el Reglamento Interno de Orden, Higiene y Seguridad de la empresa, y que las comunicaciones vía messenger son de carácter privado y que no podían ser revisadas sin las autorizaciones de quienes las habían emitido.

En este sentido, y según se explicó respecto del sistema de correo Outlook, que claramente es una herramienta de trabajo, el análisis que hay que efectuar respecto de la afectación de la privacidad, es diverso si se trata de un sistema creado por la empresa, que permitiría un mayor control del empleador por su carácter marcado de herramienta de trabajo (pago de licencias, etc.), o de otro de uso masivo o gratuito, como una cuenta común Gmail o un chat messenger, en los que el carácter de "no ser herramientas de trabajo proporcionadas por el empleador" restringe, a nuestro juicio, aún más las revisiones que este pueda efectuar a sus dependientes. En principio podría señalarse que no pueden revisarse sin autorización del trabajador.

Nuestra jurisprudencia ha tratado también el asunto del conocimiento del trabajador sobre la revisión por el empleador de sus correos, lo cual impediría considerar que se está vulnerando un derecho fundamental a la privacidad. Es el caso de la Sentencia dictada con fecha 13 de octubre de 2015, rol de ingreso 323-2015, caratulada García con Administradora, de la llustrísima Corte de Apelaciones de Valparaíso, que señaló en su considerando cuarto que al ser copiados todos los correos de los trabajadores desde las cuentas proporcionadas por la empresa a un depósito tecnológico de acceso público, no podían tener el carácter de privados. En

\footnotetext{
${ }^{10}$ El caso Barbulescu, en Rumania (año 2007), se falló de un modo similar, aunque luego el Tribunal Europeo de Derechos Humanos resolvería justamente lo contrario, en sentencia de 5 de septiembre de 2017. Se trató este caso de un trabajador (Barbulescu) que prestaba servicios como director del departamento de ventas de una empresa en Rumania. Se le encomienda, entonces, la labor de crear una cuenta de Yahoo Messenger en el computador de la empresa para comunicarse con los clientes, refiriéndole que a esa cuenta había que darle un uso exclusivamente profesional. El trabajador, sin embargo, también utilizó la cuenta para intercambiar mensajes con familiares. La empresa se percata de que el trabajador le estaba dando un uso privado a ese Messenger, y le pregunta por el asunto. El trabajador niega la existencia de dichas conversaciones con su familia, tras lo cual se le comunicó su despido alegando pérdida de confianza. El tribunal Rumano declaró justificado el despido, fundado en que se le habría advertido al trabajador que el sistema de mensajería no podía usarse para fines privados.
} 
consecuencia, no había vulneración de la privacidad. Se establece a través de esta situación, y como comentábamos a raíz de la jurisprudencia comparada, un verdadero blindaje al empleador (desaparecería la expectativa de privacidad del trabajador), y se vislumbra una situación crítica que refiere al control permanente y continuo de la correspondencia de un trabajador.

En igual sentido, una sentencia dictada en juicio caratulado Raggio con AFP Cuprum, RIT: T-972-2015, dictada por el Primer Juzgado de Letras del Trabajo de Santiago con fecha 5 de marzo de 2016, falló en sentido similar al anterior. Un trabajador demanda por cuanto su despido habría estado fundado en información a la que su empleador accedió ingresando a su correo electrónico. Al contestar la demanda, la empresa sostuvo que no se afectó dicha garantía fundamental, señalando que en el Reglamento Interno de Orden, Higiene y Seguridad se reguló que los correos enviados por los trabajadores son copiados a un departamento de control de la empleadora, por lo que el trabajador conocía esta circunstancia de conocimiento de sus comunicaciones. Es interesante la postura de la demandada, ya que, frente a un eventual examen de proporcionalidad, no esgrimió únicamente el derecho de propiedad, sino también la privacidad de terceros aludiendo a la ley 19.628 sobre Protección de Datos Personales, ya que en razón de su giro guardaba información sensible y confidencial de terceros. Se decidió descartar la vulneración de derechos fundamentales sobre la base de que el trabajador "debía saber" que sus correos electrónicos eran vistos o revisados por su empleador. Sin embargo, nuevamente la sentencia no se hace cargo del hecho de la revisión constante de las comunicaciones del trabajador, en el sentido de si esta supera o no el examen de proporcionalidad respecto a la privacidad de los trabajadores.
De este modo, la "expectativa de privacidad" planteada en España y en nuestra jurisprudencia, como limitante de las facultades del empleador, respecto de la posibilidad de revisar los correos electrónicos de sus trabajadores, no parece acertada considerada de un modo absoluto. En efecto, se resuelve apriorísticamente una problemática sujeta a casuística, que creemos, es el único modo que asegura el resguardo de los derechos de ambas partes; la propiedad del empleador y la privacidad del trabajador.

En definitiva, nuestra jurisprudencia señala que los correos electrónicos se encuentran protegidos por el derecho constitucional a la intimidad y la vida privada ${ }^{11}$, por tanto, siempre su revisión colisionará con el derecho de propiedad del empleador y, entonces, estos deben ser objeto de la ponderación correspondiente para verificar cuál derecho fundamental primará en cada caso. A nuestro juicio la "expectativa de privacidad" debe considerarse en dicho ejercicio, sin embargo, tal criterio no puede ser considerado, de forma previa, como dirimente en favor de uno u otro derecho fundamental. Aquello equivaldría a sostener que necesariamente al estar regulado el uso del correo electrónico, y estando por tanto "blindado" el empleador, el trabajador perdería a priori su derecho a la privacidad en el uso de su correo electrónico, lo cual equivaldría a decir que, al aceptar una regulación que no acordó, sino que se le impuso - normalmente a través del Reglamento Interno de Orden, Higiene y Seguridad-, el trabajador renuncia a su derecho a la privacidad. Esto sería renunciar de antemano a una eventual vulneración de garantías constitucionales, lo que es impracticable en nuestro país por atentar en contra de la irrenunciabilidad de los derechos laborales mientras se encuentra vigente la relación laboral ${ }^{12}$.

\footnotetext{
${ }^{11}$ Véase por ejemplo causa rol 1086-2013 pronunciada por la IIma. Corte de Apelaciones de Santiago, caratulada Subsecretaría de Evaluación Subrogante con Consejo para la Transparencia, de fecha 11 de octubre de 2013. Señala el considerando $10 . .^{\circ}$ de esta sentencia que las comunicaciones privadas, como son los correos electrónicos, se encuentran cubiertos por la garantía constitucional del artículo $19 \mathrm{~N}^{\circ} 5$ de la Constitución Política.

${ }^{12}$ La llma. Corte de Apelaciones de Santiago acogió un recurso de protección deducido por la Asociación de Funcionarios de Gendarmería de Chile contra una circular de la esa institución ( $N^{\circ} 304$ de 2018), que prohibía el mal uso de redes sociales por parte de funcionarios. A priori se restringía el derecho de expresión de los trabajadores de la institución mediante una resolución. En este sentido, es preciso recordar que cuando el empleador tipifica conductas prohibidas en su propia normativa interna, dicha tipificación también debe estar sujeta al respeto de los derechos fundamentales, lo cual pugna con su aniquilación vía disposiciones internas. Causa rol 63.147-2018.
} 
La Dirección del Trabajo, a su turno, ha señalado (en sus primeros pronunciamientos al respecto; luego veremos que su criterio ha experimentado variaciones) que los correos electrónicos institucionales están protegidos por el derecho de privacidad, sin distinguir si corresponde a correos enviados o recibidos. Indica que nunca podrán ser revisados por el empleador, sin perjuicio de que es legítimo regular el acceso, envío y sistema de soporte de ellos. Dicha postura consta en el Ord. $N^{\circ} 1.147 / 34$, de fecha 21 de marzo de 2005, el cual señala, en lo pertinente:

En consecuencia, de la inviolabilidad citada se seguiría la imposibilidad de que la empresa revise el contenido de los correos electrónicos de sus trabajadores, tanto los enviado como los recibidos, sin perjuicio de la facultad empresarial de regular el acceso y el envío de dichos correos electrónicos, como establecer restricciones sobre el uso de los sistemas de soporte de dichos correos en la empresa.

Resulta claro para el referido órgano administrativo, que los correos electrónicos de cualquier naturaleza y sin distinción de si corresponden a correos enviados o recibidos, forman parte del ámbito protegido por la privacidad como derecho fundamental del que goza todo trabajador en su calidad de ciudadano.

No obstante lo señalado por el ente administrativo laboral, una sentencia de 2004 (año anterior al dictamen citado arriba), dictada por la Corte de Apelaciones de Santiago, caratulada De la Puente, María Consuelo y otros con Ministra en Visita Extraordinaria, Sra. Gloria Ana Chevesic, ROL: 7001-2004, da cuenta de que no se considera, per se, que la revisión del contenido de los correos electrónicos vulnere derechos. Aunque es preciso consignar que este caso no estaba vinculado a la relación laboral.
El presente caso consistió en una acción de protección en contra de la referida ministra por cuanto, en el marco de una investigación criminal, habría ordenado la incautación de correos electrónicos de los recurrentes sin ser estos parte de los investigados y -en lo que importa para este trabajo - sin distinguir si los correos incautados eran públicos o privados, lo cual afectaría la garantía constitucional del artículo $19 \mathrm{~N}^{\circ} 5$ de la Constitución Política de la República. Al evacuar el informe, la ministra en visita sostuvo que fue informada de que resultaba imposible separar comunicaciones privadas de las públicas de los archivos que serían objeto de análisis, asegurando que estableció medidas de resguardo a la privacidad de los recurrentes para que estos no fueren conocidos por terceros ajenos a la investigación.

Al conocer de este recurso, la Corte de Apelaciones de Santiago lo rechazó y, para desestimar la alegación de los recurrentes consistente en que la no distinción sobre la incautación de correos entre públicos y privados afectaba su privacidad, sostuvo que no era posible acoger esta denuncia de infracción por cuanto resultaba imposible separar los correos electrónicos de carácter personal de aquellos que debían ser investigados ${ }^{13}$ :

El criterio establecido por la Corte es relevante para este trabajo por cuanto sienta que no puede estimarse a priori una afectación a la privacidad el revisar los correos electrónicos, si es que resulta imposible separar los que son de carácter público de los privados. Ahora, si se aplica lo expuesto a la relación laboral, sería posible concluir que un empleador podría efectivamente revisar los correos electrónicos de sus trabajadores, siempre y cuando sea por razones justificadas y garantice que su contenido no sea difundido.

${ }^{13}$ En dicho sentido la Corte sostuvo: "A mayor abundamiento, y de estimar que en las cintas ordenadas incautar, junto con la información propia del servicio, también se contendrían correos electrónicos de carácter personal y privado de los funcionarios estatales, por la indivisibilidad de la misma, hacía imposible que la señora Jueza estuviera en condiciones de identificar y clasificar, a priori, cada uno de los documentos contenidos en ellas". 


\section{Proporcionalidad en la limitación al derecho de privacidad}

Ya analizado qué debe entenderse por privacidad, y a su vez que dentro de dicha garantía fundamental se encuentran amparados los correos electrónicos que utiliza el trabajador, corresponde analizar la legitimidad de limitar este derecho, en pro del derecho de propiedad del empleador. Debemos analizar entonces la proporcionalidad de tal limitación, consistente en la revisión de correos electrónicos.

Tal como hemos indicado previamente, la Dirección del Trabajo frente a la interrogante relativa a si puede revisar el empleador los correos electrónicos de sus trabajadores, sostuvo derechamente que ello no es posible indicando:

...será entonces el empleador quién podrá tomar la iniciativa para formalizar esta normativa interna de la empresa y, en el ámbito de sus facultades de administración, podrá también incorporar preceptos a este reglamento con el fin específico de regular, limitar o restringir el empleo de los correos electrónicos por los dependientes...esta regulación podrá recaer en el uso del correo electrónico, no en la garantía constitucional de inviolabilidad de la comunicación privada... el empleador podrá regular las condiciones de uso de los correos electrónicos, cubriendo los casos y situaciones descritos precedentemente y otros, pero en ningún caso - ni por reglamento interno ni por acuerdo de las partes - podrá regularse el ejercicio mismo de la respectiva garantía constitucional ${ }^{14}$.

Cabe señalar que la Dirección del Trabajo con posterioridad reafirmó su postura en Dictamen Ord. N ${ }^{\circ}$ 1147/34 de fecha 21 de marzo de 2005 al denegar la reconsideración del dictamen antes mencionado ${ }^{15}$.
La misma postura es posible apreciar en Dictamen Ord. N ${ }^{\circ} 3441 / 072$ de fecha 20 de agosto de 2008, en el cual la autoridad administrativa indicó:

No se discute, ciertamente, en el caso que nos ocupa, que el computador no es un efecto personal del trabajador, sino una herramienta de trabajo proporcionada por su empleador. Pero lo anterior, no excluye que, en el uso de tal herramienta de trabajo, puedan producirse conflictos que afecten la intimidad de los trabajadores, en lo referido al correo electrónico (respecto al cual este Servicio ha fijado en Dict. №260/19 de 14.01.2002, la doctrina según la cual "de acuerdo a las facultades con que cuenta el empleador para administrar su empresa, puede regular las condiciones, frecuencia y oportunidad de uso de los correos electrónicos de la empresa, pero en ningún caso podrá tener acceso a la correspondencia electrónica privada enviada y recibida por los trabajadores $)^{16}$.

De la lectura del Ordinario anterior no queda lugar a dudas de que la Dirección del Trabajo estima que la revisión de correos electrónicos es vulneradora de derechos fundamentales, pero a nuestro juicio no nos podemos quedar ahí, ya que ello no deslegitima la posibilidad de revisión de los mismos. En efecto, el artículo 154 del Código del Trabajo señala:

Las obligaciones y prohibiciones a que hace referencia el número 5 de este artículo, y, en general, toda medida de control, sólo podrán efectuarse por los medios idóneos y concordantes con la relación laboral y, en todo caso, su aplicación deberá ser general,

\footnotetext{
${ }_{14}$ Dictamen Ord. N²60/19 de fecha 24 de enero del año 2002. Recuperado de http://www.dt.gob.cl/legislacion/1611/w3-article-63171. html.

${ }^{15}$ En dicha oportunidad la Dirección del Trabajo resolvió: "En consecuencia, de la inviolabilidad citada se seguiría la imposibilidad de que la empresa revise el contenido de los correos electrónicos de sus trabajadores, tanto los enviado como los recibidos, sin perjuicio de la facultad empresarial de regular el acceso y el envío de dichos correos electrónicos, como establecer restricciones sobre el uso de los sistemas de soporte de dichos correo en la empresa". Recuperado de http://www.dt.gob.cl/1601/w3-article-81104.html.

${ }^{16}$ Recuperado de http://www.dt.gob.cl/legislacion/1611/w3-printer-95955.html.
} 
garantizándose la impersonalidad de la medida, para respetar la dignidad del trabajador.

El artículo citado es relevante porque el hecho de que la jurisprudencia administrativa considere que los correos electrónicos recibidos o enviados están amparados en el derecho a la privacidad de los trabajadores, no debe paralizar al empleador. Es por ello que con posterioridad a los referidos dictámenes, la Dirección del Trabajo emitió la circular No 2210/035 de fecha 22 de junio de 2009, en la cual, al referirse a los derechos fundamentales, señaló que las medidas de control a los trabajadores - siendo una de ellas la revisión de correos electrónicos - eran posibles, siempre y cuando dichas formas de control estuvieren reguladas en el Reglamento Interno de Orden, Higiene y Seguridad, fueran realizadas por medios idóneos, impersonales, de aplicación generalizada, que su aplicación no derive en el abuso de facultades o que se adopten conductas prepoliciales, y que en su implementación se respete la dignidad de los trabajadores ${ }^{17}$.
Lo señalado por la Dirección del Trabajo, y sin anticipar nuestras conclusiones, abre un camino correcto en el planteamiento del manejo de la problemática de revisión de correos electrónicos, ya que por una parte reconoce la existencia de un derecho fundamental, pero a la vez que considera que este no lo es de manera absoluta, sino que puede verse limitado siempre y cuando se adopten los resguardos correspondientes. Lo anterior, por cuanto las relaciones laborales tienen tal nivel de particularidades que en ciertos casos puede ser aconsejable una revisión de los correos electrónicos por estar en juego otros bienes jurídicos igualmente valiosos como la intimidad de terceros, los clientes del empleador o bien, la propia actividad económica de este último.

Sin perjuicio de lo expuesto, la adopción de las medidas antes señaladas no obsta a que la solución que finalmente se adopte será mediante un análisis caso a caso de la colisión de derechos en conflicto $^{18}$, tal y como señala la doctrina frente a un conflicto similar entre trabajador y empleador: "Se debiese adoptar una solución que

\footnotetext{
${ }^{17}$ La Dirección del Trabajo sostuvo: "En lo que se refiere a los límites del poder del empleador frente al control y revisión de sus trabajadores y/o de sus efectos personales, se ha resuelto con anterioridad, que resulta lícito que el empleador plantee medidas de control y revisión pero es necesario que tales medidas "se integren en sistemas que sean compatibles con el respeto de la honra y dignidad de los trabajadores" y, en función de este objetivo se requiere que los sistemas de prevención "sean técnicos y despersonalizados", y que, por ende, se "apliquen mediante mecanismos automáticos y de sorteo", que "eviten que su operación o funcionamiento se produzca frente a presunciones de actos o conductas ilícitas concretas." A partir de la verificación de los efectos lesivos que para los derechos fundamentales suponía el uso de ciertas medidas de control por parte del empleador, lesivas para los derechos fundamentales de los trabajadores, se establecieron tres condiciones que toda medida de revisión y de control debían respetar, a saber: a) Las medidas de revisión y control de personas, de sus efectos privados o de sus casilleros, al importar un límite a la privacidad de las personas, deben necesariamente incorporarse al texto normativo que la ley establece para el efecto, esto es, el Reglamento Interno de la empresa, dictado en conformidad a la ley; b) Las medidas de revisión y control deben ser idóneas a los objetivos perseguidos como son el mantenimiento del orden, la higiene y la seguridad de la persona y sus trabajadores, no debiendo importar actos ilegales o arbitrarios por parte del empleador, según lo señala la Constitución en su artículo 20, como por ejemplo, la selección discrecional de las personas a revisar o la implementación de medidas extrañas e inconducentes a los objetivos señalados, y, c) las medidas, además, no deben tener un carácter pre policial, investigatorio o represivo frente a supuestos o presuntos hechos ilícitos dentro de la empresa, sino un carácter puramente preventivo y despersonalizado, siendo requisito "sine qua non" para la legalidad de estas medidas de revisión y control, el que sean operadas a través de un mecanismo o sistema de selección, cuyas características fundamentales son la universalidad y la despersonalización de las revisiones. Para el caso que operara una selección de operarios, se ha dispuesto que la revisión deberá ser aleatoria. Las condiciones arriba señaladas, importan que si las medidas de revisión y de control deben ser operadas a través de un sistema de selección, sus características fundamentales deberán ser la universalidad y la aleatoriedad de las revisiones. De este modo, las medidas de control de las personas que serán objeto de la revisión pueden lícitamente implementarse a través de dos modalidades: en primer lugar, hacer recaer la revisión sobre todo el personal de la empresa o sección, o en segundo lugar, establecer un mecanismo de selección que garantice la aleatoriedad de la misma, a través de un sistema de sorteo que la empresa debe explicitar en el Reglamento señalado". Recuperado de http://www.dt.gob.cl/legislacion/1611/w3-article-96717.html.

${ }^{18}$ En el mismo sentido, frente a una situación análoga referida a la intimidad, Ugarte $(2011,20)$ indica: "Y ¿qué ocurre si el empleador tiene buenas razones de higiene y seguridad para exigir o prohibir una indumentaria o artefacto estético determinado? Eso ya no es un problema de delimitación del derecho de intimidad del trabajador, sino de su restricción por una eventual colisión de derechos fundamentales, cuestión que debe ser resuelta en la etapa de ponderación...".
} 
reconozca al menos en parte ambos derechos y se incline en favor del trabajador o del empleador dependiendo de las circunstancias específicas de cada caso en particular" (Figueroa, 2014, p. 118).

En este sentido, una sentencia dictada en juicio caratulado Negrete Herrera, Jorge con Gesfor S.A., RIT: T-385-2011, dictada por el Segundo Juzgado de Letras del Trabajo de Santiago con fecha 15 de diciembre de 2011, condena a la empresa por vulneración de la privacidad en la relación laboral. Sostuvo el trabajador que habría sido citado a una reunión con su jefatura y ciertos gerentes, quienes, teniendo un correo electrónico en mano enviado por él a un extrabajador, le habrían tratado de "desleal" y "traidor", para luego despedirlo por la causal del artículo 160 № 2 del Código del Trabajo, esto es, negociaciones que ejecute el trabajador dentro del giro del negocio y que hubieren sido prohibidas por escrito en el respectivo contrato por el empleador.

Indicó el trabajador que la empresa habría accedido al correo aludido por cuanto se redireccionó la cuenta de correo electrónico a un subgerente. La empresa, al contestar la denuncia, sostuvo que este redireccionamiento de los correos del ex trabajador fue de público conocimiento en la empresa, incluido el demandante. Refirió, además, que no se afectó la privacidad del actor, ya que este, al enviar el correo a un trabajador que ya no usaba esa casilla de correo electrónico, decidió compartir dicha información con la empresa. Finalmente, sostuvo que el correo no tenía el carácter de privado.

Pues bien, en este caso la denuncia fue acogida por el tribunal y en él se realizan algunos razonamientos interesantes de analizar. En primer lugar, el fallo concluye que el correo electrónico es privado, destacando que dicha nota se advierte del contenido del mensaje y no del hecho de estar inserto este en un correo propio del trabajador o uno institucional. Además, señala que los usuarios tenían la legítima expectativa de que tal comunicación no sería leída por terceros ${ }^{19}$. Por otra parte, la sentencia reprocha expresamente el redireccionamiento de los correos efectuado por la empresa, señalando que aquello no le resta el carácter de privado a la comunicación ${ }^{20}$. Por otra parte, la sentenciadora sostiene que se han acreditado conductas vulneradoras, las cuales individualiza en su considerando octavo, y serían, por una parte, redireccionar el correo de un extrabajador y por la otra, acceder a un correo electrónico que sabía el empleador no estaba destinado a él.

Es relevante la conclusión del considerando noveno de esta sentencia, en la que se efectúa un examen de ponderación (¿fue justificada la medida?), señalando expresamente que la medida no fue necesaria:

No obstante la medida no se observa como "necesaria" $\mathrm{y}$, en este punto, la misma demandada reconoce que existían alternativas más benignas con el derecho fundamental en cuestión... Si a lo anterior agregamos que la medida no estaba reglamentada ni puesta formalmente en conocimiento de los empleados, no se puede catalogar como una medida lícita de implementar y, por ende, deviene en ilícita cualquier información privada a la que haya accedido por ese medio... la medida de la empresa impresiona como evidentemente desproporcionada, tomando en cuenta los derechos fundamentales en conflicto.

El análisis contenido en el fallo resulta sumamente interesante por diversos motivos. El primero es que

\footnotetext{
${ }^{19}$ Así lo señala el propio fallo en su considerando séptimo: “...Cabe señalar que el carácter de privado del documento en cuestión no se ve afectado por el hecho que la empresa sea dueña de la casilla institucional a la cual se envió, puesto que lo que le da el carácter de privado es que tanto el remitente como los demás destinatarios tenían la legítima expectativa de que su comunicación no fuera interceptada ni conocida por personas diversas a las que el correo fuera dirigido..."

${ }^{20}$ El fallo señala en dicho sentido: "Tampoco pierde el carácter de privado la comunicación en cuestión por el hecho que el trabajador que tenía asignada la cuenta intervenida o redireccionada haya dejado de prestar servicios para la empresa... En este sentido, el redireccionamiento del correo del sr. Soto es el medio por el cual la empresa accede a la comunicación privada del demandante y, en cuanto medio, puede revisarse su legitimidad, sin embargo el acto que se estima lesivo, específicamente, alude a la decisión de conocer el contenido de una comunicación privada que evidentemente no iba dirigida a la empresa y utilizar dicha información en contra de sus destinatarios".
} 
la sentencia reconoce que la revisión de los correos electrónicos por el empleador supone un conflicto de derechos fundamentales y, por lo tanto, debe revisarse en cada caso su solución. A su vez, la sentencia realiza claramente un análisis pormenorizado de la conducta del empleador, cuestionándose directamente la validez del redireccionamiento de la información que es enviada al correo de un trabajador.

Otro fallo relevante en la materia, pero distinto al anterior por lo que se resuelve en instancia, a propósito de la debida ponderación que es obligatoria efectuar por el juez en virtud del artículo 493 del Código del Trabajo (que no existió como veremos), es el caratulado Moreno con Cadem, RIT T-989-2016, del 1. Juzgado de Letras del Trabajo de Santiago. Este juicio versa sobre el despido de una trabajadora que desempeñaba el cargo de directora de campo de la empresa, esto es un cargo de confianza, por entregar información confidencial a la competencia, a través de su correo corporativo. La actora en su demanda indica que la empresa habría accedido a sus correos electrónicos, en los que entregaba dicha información, de modo irregular, esto es contra lo señalado en el reglamento interno de la empresa; sin autorización y sin conocimiento de la trabajadora. Cadem en su contestación aludió a que se buscó censurar una conducta de la ex trabajadora, al sospechar fundadamente (se encontraron en su puesto de trabajo, de modo fortuito, encuestas de la empresa de la competencia) que la actora podía estar difundiendo a una empresa de la competencia información recopilada con motivo de los estudios que realizaba, datos que por ley la empresa debe proteger, en virtud de la ley 19.628 sobre protección de la vida privada.

La sentencia de la instancia comete el grave error, como adelantamos, de no realizar la ponderación de rigor al tenor del artículo 493 del Código del Trabajo, es decir no hace el ejercicio de, una vez constatados indicios de vulneración, analizar la idoneidad, necesidad y proporcionalidad en sentido estricto de la medida empresarial, lo cual vimos que la sentencia recién revisada sí realiza. La sentencia se limita a señalar, en su considerando noveno, que se revisaron -por la empresa- los correos electrónicos de la trabajadora, sin su consentimiento o autorización, para posteriormente fundar un despido en la información así obtenida. Señala que el reglamento interno de la empresa permitía revisar los computadores de los trabajadores con la presencia del trabajador que así lo solicite, pero que la empresa no habría cumplido con dar este aviso a la trabajadora. En virtud de esta conducta de la empresa, el juez de instancia la condena por vulneración de derechos fundamentales.

Sin embargo, la empresa deduce recurso de nulidad precisamente por la circunstancia que venimos comentando, esto es, por la falta de análisis de justificación, necesidad y proporcionalidad de la medida de revisión de correos electrónicos de la trabajadora por parte de la empresa. Este recurso es acogido ${ }^{21}$, señalando la Corte, en el considerando tercero del fallo que

no se vierte a continuación razonamiento alguno respecto de las defensas esgrimida por la demandada para demostrar que su conducta lesiva se debió a motivos y objetivos razonables. En efecto no se dan razones por qué el actuar de Cadem lo fue "sin justificación suficiente, en forma grave y desproporcionada". Es decir, la sentencia no analiza una cuestión central de las acciones de tutela, cual es la justificación de la denunciada y la proporcionalidad de la medida adoptada, soslayando la tesis planteada por Cadem en orden a que su proceder obedeció a un deber legal de garantizar datos de la vida privada de los encuestados...

Posteriormente esta trabajadora deduciría recurso de unificación de jurisprudencia, el cual sería rechazado ${ }^{22}$.

En consecuencia, el análisis de justificación, necesidad y proporcionalidad de la medida es indispensable al momento de determinar si se vulneró el derecho fundamental de un trabajador o si, por el contrario, es

${ }^{21}$ Rol de ingreso N ${ }^{\circ} 2134-2017$ ICA Santiago.

${ }^{22}$ Rol de ingreso 6247-2018 Excelentísima Corte Suprema de Justicia. 
razonable y justificada tal medida, en atención a otros derechos, propios o de terceros, que se pretendía proteger por el empleador. De todos modos, este fallo de la llustrísima Corte de Apelaciones de Santiago Moreno con Cadem reprocha al juzgador que no haya efectuado tal análisis, señalando en el considerando cuarto, que la influencia sustancial del vicio en la falta de análisis de ponderación, era un "aspecto central del juicio", que debió haber efectuado y no lo hizo, y que por ello, la sentencia es nula.

\section{Conclusiones}

A lo largo de esta presentación se pudo apreciar que la privacidad es un concepto que no está del todo claro a nivel jurisprudencial, sin perjuicio de que existe consenso en cuanto a la necesidad de su protección.

Por otra parte, se revisó si eran parte del ámbito de protección de dicha garantía los correos electrónicos de los trabajadores frente a lo cual se pudo arribar a una postura afirmativa.

El criterio de la "pérdida de la expectativa de privacidad" no puede utilizarse de modo absoluto para zanjar la problemática de vulneración de la privacidad de un trabajador.

El control que puede establecer el empleador respecto de correos electrónicos institucionales, no es el mismo que puede aplicarse respecto de cuentas Gmail, Yahoo u otras, que se hayan creado en una empresa para efectos de comunicarse con clientes u otros fines. En este último caso, las medidas de control no pueden ser tan intensas y requieren en todo caso de autorización del trabajador para su revisión.
No puede establecerse un medio de control de los correos electrónicos que importe una revisión constante y permanente de los mismos, ya que aparece como una medida excesivamente intensa que no tiene justificación. Al contrario, es desmedida en aras de cualquier fin empresarial que se quiera buscar o proteger, los cuales pueden lograrse a través de otro tipo de controles menos invasivos.

Las formas de control sobre los correos electrónicos deben estar reguladas en el Reglamento Interno de Orden, Higiene y Seguridad, realizarse por medios idóneos, impersonales, de aplicación generalizada. Su aplicación no puede derivar en el abuso de facultades y no pueden implicar la adopción de conductas prepoliciales. Además, en su implementación, debe respetarse la dignidad de los trabajadores.

Para determinar si se vulneró el derecho fundamental de un trabajador a la privacidad, se debe siempre efectuar un análisis particular del caso, una vez hallados indicios de vulneración, revisando si la medida empresarial tiene justificación, es necesaria y es proporcionada en un sentido estricto. 


\section{Referencias}

Agustina, J. R. (2009). Privacidad del trabajador versus deberes de prevención del delito en la empresa. Buenos Aires: Ed. BdF.

Baylos, A. (1991). Derecho del Trabajo: un modelo para armar. Madrid: Trotta.

Cea Egaña, J. L. (2003). Derecho Constitucional Chileno II: Deberes y Garantías. Santiago: Ediciones Universidad Católica de Chile.

Comisión de Estudio de un Anteproyecto de la Nueva Constitución. (1973) Acta Oficial № 129. República de Chile.

Desdentado, A. y Muñoz, A. B. (2012). Control Informático, Videovigilancia y Protección de Datos en el Trabajo. Valladolid: Lex Nova

Figueroa, R. (2014). Privacidad. Santiago, Chile: Ediciones Diego Portales.

Gamonal, S. (2011). Trabajo y Derecho ( $2^{\mathrm{a}}$ ed). Santiago de Chile: Legalpublishing.

Maqueo, M.S., Moreno, J. y Recio, M. (2017). Protección de datos personales, privacidad y vida privada: la inquietante búsqueda de un equilibrio global necesario. Revista de derecho, (30), 77-96. Recuperado de http:// dx.doi.org/10.4067/S0718-09502017000100004 [9 de agosto de 2019].

Martínez de Pisón, J. (1997). Vida privada e intimidad: implicaciones y perversiones. Anuario de filosofía del derecho, 14, 717-738.

Piñera, J. (1990). La Revolución Laboral en Chile (3ª ed.). Santiago, Chile: Zig-Zag.

Ugarte, J. L. (2000). El derecho a la intimidad y la relación laboral. Boletín Oficial de la Dirección del Trabajo, (139).

Ugarte, J. L. (2010). Tutela de derechos fundamentales del trabajador ( $\left.3^{\circ} \mathrm{Ed}\right)$. Santiago, Chile: Legalpublishing, Ugarte, J. L. (2011). El nuevo derecho del trabajo ( $3^{\mathrm{a}}$ ed.). Santiago de Chile: Thompson Reuthers.

Ugarte, J. L. (2011). Privacidad, Trabajo y Derechos Fundamentales. Estudios Constitucionales, 9 (1). 13-36.

Recuperado de http://dx.doi.org/10.4067/S0718-52002011000100002 [fecha consulta 22 de mayo de 2019].

\section{Jurisprudencia}

Corte de Apelaciones de Santiago, 25 de octubre de 2018, Rol №63147-2018.

Corte de Apelaciones de Santiago, 11 de octubre de 2013, Rol №1086-2013.

Corte de Apelaciones de Santiago, 9 de febrero de 2018, Rol N²134-2017.

Corte de Apelaciones de Santiago, 6 de diciembre 2004, Rol N7001-2004.

Corte de Apelaciones de Valparaíso, 13 de octubre de 2015, Rol №323-2015.

Corte Suprema de Justicia, 21 de enero de 2019, Rol N6247-2018.

Dirección del Trabajo, 20 de agosto de 2008, Dictamen Ord. №3441/72.

Dirección del Trabajo, 21 de marzo de 2005, Dictamen Ord. №1.147/34.

Dirección del Trabajo, 21 de marzo de 2005, Dictamen Ord. №1147/34.

Dirección del Trabajo, 22 de junio de 2009. Circular №2210/035.

Dirección del Trabajo, 24 de enero del año 2002, Dictamen Ord. №260/19.

Juzgado de Letras del Trabajo de Copiapó, 15 de septiembre de 2008, Rit T-1-2008.

Primer Juzgado de Letras del Trabajo de Santiago, 13 de septiembre de 2017, RIT T-989-2016.

Primer Juzgado de Letras del Trabajo de Santiago, 5 de marzo de 2016, RIT: T-972-2015.

Segundo Juzgado de Letras del Trabajo de Santiago, 15 de diciembre de 2011, RIT: T-385-2011.

Tribunal Constitucional de España, №170-2013, 12 de enero 2016. 